\title{
Uterine Rupture and Associated Factors During Labor Amongst Women Delivered in Saudi Hajjah Hospital in Hajjah City North West Yemen
}

\author{
Abdullah AD Al Rukeimi ${ }^{1,2}$, Eishah Mohammed Al Shaibani ${ }^{2}$, Hassan A Al Shamahy ${ }^{3 *}$, Ahmed Mohamed \\ Al Hadad ${ }^{2}$, Hadeel Mohammed Al Tabreezi ${ }^{2}$, Haitham Abdulqawi Al Khorasani ${ }^{2}$ and Samera Muthanna \\ Nasser Dainamah ${ }^{4}$
}

${ }^{1}$ Department of Obstetrics and gynecology, Saudi Hajjah Hospital, Yemen

${ }^{2}$ Department of community Medicine, Sana'a University

${ }^{3}$ Department of Medical Microbiology and Clinical Immunology, Sana'a University, Republic of Yemen

${ }^{4}$ Department of Obstetrics and gynecology, Al Sabian University Hospital, Yemen

*Corresponding author: Hassan A Al Shamahy, Faculty of Medicine and

Heath Sciences, Sana'a University, P.O. Box 775 Sana'a, Yemen.

Received Date: October 22, 2018

Published Date: October 29, 2018

\begin{abstract}
Background: Uterine rupture lead to elevated maternal and neonatal mortality in a lot of rural places in the world, while in Yemen in both rural and urban places. This study was conducted aiming to determine the prevalence and risk factors of uterine rupture in women who delivered in Saudi Hospital in Hajjah city, Yemen.

Method and materials: Service based cross sectional study was done. The data were obtained by filling standard questionnaire from 111 uterine rupture cases and 111 non-uterine rupture comparative controls.

Result: The 2-year period of record review in the obstetrics ward shows 3,457 deliveries were conducted 111 of them had uterine rupture (incidence: 1:31). The mean maternal age of females had uterine rupture was 26 years with SD 7.4 years. For risk factors of uterine rupture, there was a highly significant association between uterine rupture occurrence and parity $(>5)(0 R=3.4$, $\mathrm{pv}<0.001)$, illiteracy of females $(\mathrm{OR}=14.2, \mathrm{pv}<0.001)$, residence far from hospitals $(\mathrm{OR}=2.6$ times, $\mathrm{pv}<0.001)$, poverty $(\mathrm{OR}=29.2$, $\mathrm{pv}<0.001)$, attending ANC for less than 2 visits during pregnancy (OR=29.2, pv<0.001), using uterotonic drugs to induce or augment labor $(\mathrm{OR}=4.3 \mathrm{pv}=0.01)$, home as initial place of deliveries $(\mathrm{OR}=6.8, \mathrm{pv}<0.001)$.

Conclusion: Uterine rupture is one of the major causes of maternal morbidity and mortality in our Hospital in Hajjah. The hospital should develop strong collaborative and integration methods with catchment of healthy facility and educative campaign to decrease prevalence of uterine rupture and its impact in the surrounding Hajjah governorate.
\end{abstract}

Keywords: Uterine rupture, Risk factors, Hajjah, Yemen

\section{Introduction}

Global, around 340,000 to 500,000 women die annually as a result of pregnancy and child birth complications. The greater part of these cases happens in low income countries; including Sub-Sahara Africa and countries like Yemen [1]. In addition, uterine rupture is one of the major obstetric complications of labor and directly play a role to perinatal and maternal morbidity and mortality [2]. The prevalence of uterine rupture in developed countries was 0.92 . However, in developing countries: $1.9 \%$ in Central Africa, $18 \%$ in Burkina Faso and 25\% in Ethiopia [3]. Also, the top four causes of maternal mortality in developing countries were obstructed labor and uterine rupture (36\%), hemorrhage (22\%), hypertensive disorders of pregnancy (19\%) and sepsis/infection (13\%) [3-5]. Moreover, in Yemen and some Sub-Sahara Africa countries more than $50 \%$ of deliveries were attended at home $[3,5,6]$. As well as, phase I delay (delay in decision to seek care) contributed about $25 \%$ of maternal deaths in most developing countries including Yemen $[3,5,6]$. For this, reason Ministry of Health should initiate free maternity services at health center and hospital level. Uterine rupture was the third common cause of death in Sana'a 
city hospitals [6]. Therefore, is important to improve availability, accessibility and utilization of the essential emergency obstetric care services to decrease maternal loss. Plus, skilled attendance of labor coupled with early referral to the next higher level for better and timely intervention is equally important [7].

A study conducted in Africa and Asia the main associated factors for uterine rupture were obstructed labor alone, and use of oxytocin in already obstructed labor, constituted oxytocin use, previous uterine scar and intrauterine manipulation by traditional birth attendants $[3,8,9]$. It is possible to prevent most maternal deaths and disabilities with known and effective interventions, although this needs the right kind of information on why women are dying or facing lifelong disabilities. As many literatures decide that uterine rupture is one of the causes for maternal death. But factors resulting uterine rupture differ from one study to another. In particular this study was aimed to determine the prevalence uterine rupture and associated factors during labor among women who delivered in Saudi Hospital in Hajjah city, North West Yemen.

\section{Subjects and Methods}

\section{Study area and study period}

Saudi Hospital is a public hospital found in Hajjah city, which is located in Hajjah governorate in the North West of Yemen, about 200 km North West of the capital Sana'a. The hospital provides health service to more than 2000,000 populations. There were 3,457 deliveries conducted per two year from annual report of hospital, in obstetric ward. The study was conducted during September 1-2014 and August 31-2016. It was based on comparative cross-sectional study (Table 1).

Table 1: Logistic regression result of factors associated with uterine rupture among women delivered in Saudi hospital Hajjah from 1 September 2014 to 31 August 2016.

\begin{tabular}{|c|c|c|c|c|c|c|c|}
\hline \multirow{2}{*}{ Factors } & \multicolumn{2}{|c|}{ Cases $\mathrm{n}=111$} & \multicolumn{2}{|c|}{ Controls $n=111$} & \multirow{2}{*}{ OR } & \multirow{2}{*}{ CI 95\% } & \multirow{2}{*}{ PV } \\
\hline & No & $\%$ & No & $\%$ & & & \\
\hline Parity: $<5$ & 73 & 66 & 39 & 35.1 & 3.4 & $1.6-6.8$ & $<0.001$ \\
\hline Parity: > 5 or nil & 38 & 34 & 72 & 64.9 & 0.2 & 0.14-0.5 & $<0.001$ \\
\hline \multicolumn{8}{|c|}{ Educational level } \\
\hline Illiterate & 68 & 61 & 11 & 9.9 & 14.2 & $5.2-38$ & $<0.001$ \\
\hline Primary & 27 & 24 & 13 & 11.7 & 2.3 & $0.9-6.1$ & 0.07 \\
\hline Secondary & 15 & 14 & 47 & 42.3 & 0.21 & $0.09-0.4$ & $<0.001$ \\
\hline University & 1 & 0.9 & 40 & 36 & 0.17 & $0.002-0.1$ & $<0.001$ \\
\hline \multicolumn{8}{|c|}{ Residence Resident $>10 \mathrm{~km}$ from hospital } \\
\hline Urban & 53 & 48 & 78 & 70.3 & 0.39 & $0.19-0.7$ & $<0.001$ \\
\hline Rural & 58 & 52 & 33 & 29.7 & 2.6 & $1.3-5.2$ & $<0.001$ \\
\hline \multicolumn{8}{|l|}{ Social economic } \\
\hline Poor & 99 & 89 & 24 & 21.6 & 29.2 & $11.9-71$ & $<0.001$ \\
\hline Adequate & 12 & 11 & 87 & 78.4 & 0.03 & $0.01-0.07$ & $<0.001$ \\
\hline \multicolumn{8}{|l|}{ Mode of delivery } \\
\hline Spontaneous & 29 & 26 & 40 & 36 & 0.62 & $0.3-1.2$ & 0.2 \\
\hline Attendant & 58 & 52 & 64 & 57.7 & 0.79 & $0.4-1.5$ & 0.49 \\
\hline Induction/augmentation & 24 & 22 & 7 & 6.3 & 4.3 & $1.2-15$ & 0.01 \\
\hline \multicolumn{8}{|c|}{ Attending ANC during pregnancy } \\
\hline Less than 2 & 99 & 89 & 24 & 21.6 & 29 & 11.9-71 & $<0.001$ \\
\hline Greater than 2 & 12 & 11 & 87 & 78.4 & 0.03 & $0.01-0.08$ & $<0.001$ \\
\hline \multicolumn{8}{|l|}{ Place of onset the delivery } \\
\hline At home (phase I delay) & 76 & 68 & 27 & 24.3 & 6.8 & $3.2-14.7$ & $<0.001$ \\
\hline Centers (phase I delay) & 33 & 30 & 15 & 13.5 & 2.6 & $1.1-6.3$ & 0.03 \\
\hline Hospitals & 2 & 1.8 & 69 & 62.2 & 0.01 & $0.002-0.005$ & $<0.001$ \\
\hline
\end{tabular}

OR Odds ratio = Relative risk

$95 \% \mathrm{Cl} \quad 95 \%$ Confidence intervals

$X^{2} \quad$ Chi-square $=3.9$ or more is significant

pv Probability value $=0.05$ or less is significant

\section{Population}

a. Source of population: All case notes of clients who received care for delivery in obstetric ward in Saudi Hajjah Hospital. b. Study population: All sampled case notes of clients who received care for delivery in SH hospital, from September 1, 2014 to August 31, 2016. 
c. Inclusion criteria: All case notes of delivery after 28 weeks of gestational age that were managed in obstetric case from September 1, 2014 to August 31, 2016.

d. Exclusion criteria: Pregnancy terminated before 28 weeks of gestational age.

e. Sample size and sampling techniques: Single population proportion formula was used to calculate sample size. The final sample size was 111 among 3457 cases from Obstetrics ward registry book.

\section{Study variables}

Dependent variable: Uterine rupture Interdependent variables: Socio demography, maternal age, marital status and address.

Obstetrics factors included: ANC visit, gravida, parity, obstructed labor, induction/augmentation, referred from facility, obstetric procedure (instrumentation), fetal presentation and birth out-come.

\section{Method of Data Analysis}

\section{Quantitative data}

EPI-Data Statistical software version 6 was used for data entry and analysis. After organizing and cleaning the data, important characteristics of study subjects were recorded. The data were expressed in percentages, means and standard deviations to all variables that are related to the objectives of the study. Odds ratio (association), 95\% CI, and Chi-square $\left(\chi^{2}\right)$ were done by $2 \times 2$ cross tabulation to find the association, between the independent variables and the dependent variable by comparing to 111 women attending to hospital and free from the episode. $P$ value at 0.05 or less was considered statistically significant.

\section{Ethical approval}

We obtained written consent from all cases. The study proposal was evaluated and approved by the Ethics Committee of Faculty of Medicine and Health Sciences, Sana'a University.

\section{Results}

Table 2: The age distribution of female suffering from uterine rapture attending to Saudi Hospital in Hajjah city Yemen. From $1^{\text {st }}$ of September 2014 to 31 August 2016.

\begin{tabular}{|c|c|c|}
\hline \multirow{2}{*}{ Characters Age groups } & \multicolumn{2}{|c|}{ Female n=111 } \\
\hline & No. & $\%$ \\
\hline$<20$ years & 19 & 17 \\
\hline $20-24$ years & 38 & 34 \\
\hline $25-29$ years & 25 & 23 \\
\hline$\geq 30$ years & 29 & 26 \\
\hline Total & 111 & 100 \\
\hline Mean age & 26.4 years & \\
\hline SD & 7.4 years & \\
\hline Median & 24 years & \\
\hline Mode & 23 years & \\
\hline Min-Max & $16-45$ years & \\
\hline
\end{tabular}

The 2-year period of record review in SH Hospital obstetric ward indicated the 3457 deliveries were conducted. Among 3457 sampled cases there were 111 uterine rupture cases making an incidence of 1:31. The mean maternal age of females had uterine rupture was 26 years with SD 7.4 years. The age of uterine rupture females ranged from 16 years to 45 years, $17.1 \%$ of the total females were in age group less than 20 years, $34 \%$ in $20-24$ age group, $23 \%$ in $25-29$ years age group, and $26 \%$ in $\geq 30$ years group (Table 2 ).

There was a highly significant association between uterine rupture and positive parity $(>5)(\mathrm{OR}=3.4$ times with $\mathrm{CI}=1.6-6.8$, and $\mathrm{pv}<0.001)$, illiteracy $(\mathrm{OR}=14.2$ times with $\mathrm{CI}=1.6-6.8$, and $\mathrm{pv}<$ $0.001)$, and residency in rural areas, $(\mathrm{OR}=2.6$ times with $\mathrm{CI}=1.3$ 5.2 , and $\mathrm{pv}<0.001$ ). We classified social economic of our study groups to poor and adequate, there was a high extremely significant association between poor and uterine rupture with associated risk equal to 29.2 times with $\mathrm{CI}=11.9-71$, and $\mathrm{pv}<0.001$, while a significant protected effect was found for female with adequate degree. We classified attending ANC for our study groups to less than 2 visits during pregnancy and greater than 2 times, there was a abundantly high significant association between less than 2 visit and uterine rupture with associated risk equal to 29.2 times with $\mathrm{CI}=11.9-71$, and pv $<0.001$, while a significant protected effect was found for female had 2 visits or more to ANC. When we studied mode of deliveries as risk factors for uterine rupture, there was a highly significant association between induction/augmentation delivery and uterine rupture with associated risk equal to 4.3 times with $\mathrm{CI}=1.2-15.1$, and $\mathrm{pv}=0.014$, while no association with spontaneous and attendant deliveries.

When we studied the initial place of deliveries before transfer to our hospital (phase I delayed) as risk factors for uterine rupture, there was a highly significant association between home delivery and uterine rupture with associated risk equal to 6.8 times with $\mathrm{CI}=3.2-14.7$, and pv>0.001. Also, there was a highly significant association between initial health center delivery and uterine rupture with associated risk equal to 2.6 times with $\mathrm{CI}=1.1$ 6.3 , and $p v=0.03$, while a significant protected effect was found for female whom primary delivery was in the hospital. Only 33 (30\%) of newborns were alive, while $78(70 \%)$ were dead. Also 66 $(60 \%)$ of the mothers had uterine repaired while $33(30 \%)$ had hysterectomy, while the outcome of $12(10 \%)$ of the mothers were death (Table 3).

Table 3: Maternal complications of uterine rupture in Saudi Hajjah hospital, Hajjah city, Yemen.

\begin{tabular}{|c|c|c|}
\hline Complications & Number & Percentage \\
\hline Newborn outcome & & \\
\hline Alive & 33 & 30 \\
\hline Dead & 78 & 70 \\
\hline Mother Outcome & & \\
\hline Uterine repaired & 66 & 60 \\
\hline Hysterectomy & 33 & 30 \\
\hline Death & 12 & 10 \\
\hline Total & 111 & 100 \\
\hline
\end{tabular}




\section{Discussion}

Among 3457 sampled cases there were 111 uterine rupture cases making an incidence of 1:31 which is higher than study done in Uganda in which the incidence was 1:200, also our incidence is higher than the incidence in Ghana: 1:124, Ethiopia: 1:100, and in Tanzania:1.2:500 delivers [10-12]. The possible justification for our high incidence of uterine rupture could be poor obstetric care, poor accessibility to the few available Comprehensive Emergence Obstetric Care (CEMOC) facilities in the zone.

In less and least developed countries as Yemen, uterine rupture is an important cause of maternal mortality. In our study the maternal death rate of uterine rupture mothers was 10\% (Table 3). This rate is nearly similar to the mean rate in less and least developed countries, in which it accounting for as many as $9.3 \%$ of maternal deaths [8] While our maternal deaths (10\%) was lower than that reported in the Second Report on Confidential Enquiries into Maternal Deaths in South Africa 1999-2001, in which rupture uterus caused $6.2 \%$ of deaths due to direct causes and $3.7 \%$ of all deaths $[9,13]$.

The second aim of the study was to study associated risk factors of uterine rupture. The first factor studied in our study was parity in which there was a highly significant association between uterine rupture occurrence and $>5$ parity ( $\mathrm{OR}=3.4$ times and $\mathrm{PV}<0.001)$. This is similar to a study in western Uganda in which, parity $>5$ was risk factor for uterine rupture [14]. Walsh et al. [15] confirmed our finding of high parity is important cause of uterine rupture and confirmed that it is an extremely rare case of uterine rupture in a first pregnancy.

When we studied educational level, there was a highly significant association between uterine rupture occurrence and illiteracy $(\mathrm{OR}=14.2, \mathrm{PV}<0.001$, while a significant protected effect was found for female with university level and secondary level. Our results are confirmed the importance of education in maternal health improvements and the result is similar to that reported from developing countries in which maternal illiteracy is a risk factor of uterine rupture and education is protective factors $[5,16]$. Considered residency, there was a highly significant association between a long way living from hospitals (rural areas) and uterine rupture $(\mathrm{OR}=2.6$ and $\mathrm{pv}<0.001$, while a significant protected effect was found for female resident near hospital (urban). This result is similar to Aliyu et al. [5] study in Ethiopia in which living in distance $>10 \mathrm{~km}$ from the hospital had 5.26 odds of having uterine rupture. Also, this is similar with a study in western Uganda from which, predisposing factor for uterine rupture were; living in a distance $>5$ $\mathrm{km}$ from the facility [14].

We classified social economic of our study groups to poor and adequate, poor female had 29.2 odds $(<0.001)$ having uterine rupture, while a significant protected effect was found for female with adequate degree. Our result is similar to the finding that reported from Ghana, Ethiopia and Bangladesh in which they indicated that about $60 \%$ of cases of uterine rupture were associated with poverty [3].

We classified attending ANC for our study groups to less than 2 visits during pregnancy and greater than 2 visits, there was a abundantly high significant association between less than 2 visit and uterine rupture $(\mathrm{OR}=29.2$, pv $<0.001)$, while a significant protected effect was found for female had 2 visits or more to ANC. Our result is similar to Alemayehu et al. [14] in Ethiopia in which attending ANC less resulted in 2.5 odds of having uterine rupture. Also, this result is similar with a study in western Uganda from which, predisposing factor for uterine rupture were; $<4$ antenatal visits [11].

Studying augment labor as risk factors for uterine rupture, augment labor women had 4.3 odds (PV=0.01) having uterine rupture. Our finding is similar to Topuz [17] in which the use of uterotonic drugs to induce or augment labor was a risk factor of uterine rupture. Also, there have been reports of uterine rupture when misoprostol was used in dosages above $25 \mathrm{Ag}$ vaginally $[10,18,19]$.

When we studied the phase I delay as risk factors for uterine rupture, there was a highly significant association between home delivery and uterine rupture with associated risk equal to 6.8 times ( $\mathrm{pv}<0.001)$. Also, there was a highly significant association between initial health center delivery and uterine rupture with associated risk equal to 2.6 times ( $\mathrm{pv}=0.03$ ), while a significant protected effect was found for female whom primary delivery was in the hospital. This result is similar to previous study in Yemen $[6,20]$, in Uganda, Tanzania, Nigeria and Ethiopia whereas homes and centers are the initial place of deliveries before referred women to hospitals had very high odds of having uterine rupture [8,11,14,21,22].

\section{Conclusion}

Uterine rupture is one of the major causes of maternal morbidity and mortality in our Saudi Hajjah Hospital in Hajjah city. The hospital should develop strong collaborative and integration methods with catchment of healthy facility and educative campaign to decrease prevalence of uterine rupture and its impact in the surrounding Hajjah governorate.

\section{Acknowledgment}

Authors acknowledge the financial support of Saudi Hajjah Hospital in Hajjah city, and Sana'a University, Yemen.

\section{Conflict of interest}

No conflict of interest associated with this work.

\section{References}

1. Adeoye IK, Onayade AA, Fatusin AO (2013) Incidence, determinants and perinatal outcomes of near miss maternal morbidity in Ile-Ife Nigeria: a prospective case control study. BMC Pregnancy Childbirth 13: 93.

2. World Health Organization, UNICEF, UNFPA The World Bank (2010) Trends in maternal mortality 1990 to 2008, estimates developed by WHO, UNICEF, UNFPA and the world bank, WHO Press, Geneva, Switzerland.

3. Hofmeyr GJ, Say L, Gulmezoglu AM (2005) WHO systematic review of maternal mortality and morbidity: the prevalence of uterine rupture. BJOG 112(9): 1221-1228.

4. Berhan Y, Berhan (2014) Causes of maternal mortality in Ethiopia: A significant decline in abortion related mortality. Ethiop J Health Sci 24(0 Suppl): 15-28.

5. Aliyu SB, Yizengaw TK, Lemma TB (2016) Prevalence and associated factors of uterine rupture during labor among women who delivered in Debre Markos hospital north west Ethiopia. Intern Med 6(4): 1000222. 
6. Diab AE (2005) Uterine rupture in Yemen. Saudi Med J 26(2): 264-269.

7. Dereje N, Nebiyu M (2009) Review of maternal death in Jimma university specialized hospital. Ethiop J Health Sci 19: 9-12.

8. Kidanto HL, Mwampagatwa I, van Roosmalen J (2012) Uterine rupture a retrospective analysis of causes, complications and management outcomes at Muhimbili National Hospital in Dar es Salaam, Tanzania. Tanzan J Health Res 14(3): 220-225.

9. Ibrahim SM, Umar NI, Garba NA, Bukar M (2014) HA3A reappraisal of ruptured uterus in a suburban referral hospital, North-Eastern Nigeria. Int J Med Appl Sci 3: 299-308.

10. Hofmeyr GJ (2004) Obstructed labor: using better technologies to reduce mortality. Int J Gynecol Obstet 85 Suppl 1: S62- S72.

11. Kadawa I (2010) Rupture uterus prevalence, predisposing factors and outcome among delivered woman in rural Uganda. Singapore Med J 51(1): 35-38.

12. Fofie CO, Baffoe P (2010) A two-year review of uterine rupture in a regional hospital. Ghana Med J 44(3): 98-102.

13. van den Akker T, Beatrice M, James I, van Roosmalen J (2009) Using audits to reduce the incidence of uterine rupture in a Malawian district hospital. Int J Gynaecol Obstet 107(3): 289-294.

14. Alemayehu W, Ballard K, Wright J (2012) Primary repair of obstetric uterine rupture can be safely undertaken by non-specialist clinicians in rural Ethiopia: a case series of 386 women. BJOG 120 (4):1-5.
15. Walsh CA, O’Sullivan RJ, Foley ME (2006) Unexplained prelabor uterine rupture in a term primigravida. Obstet Gynecol 108(3 Pt 2): 725-727.

16. WHO (2005). WHO systematic review of maternal mortality and morbidity: the prevalence of uterine rupture. BJOG: an International Journal of Obstetrics and Gynaecology 12: 1221-1228.

17. Topuz S (2004) Spontaneous uterine rupture at an unusual site due to placenta percreta in a 21-week twin pregnancy with previous cesarean section. Clin Exp Obstet Gynecol 31(3):239 -241.

18. Ezechi OC, Kalu BK, Njokanma FO, Nwokoro CA, Okeke GC (2004) Vaginal misoprostol induction of labor: a Nigerian hospital experience. J Obstet Gynaecol 24(3): 239-242.

19. Thomas A, Jophy R, Maskhar A, Thomas RK (2003) Uterine rupture in a primigravida with misoprostol used for induction of labor. BJOG 110(2): 217-218.

20. Dhaifalah I, Santavy J, Fingerova H (2006) Uterine rupture during pregnancy and delivery among women attending the Al-thawra hospital in Sana'a City Yemen Republic. Biomed Pap Med Fac Univ Palacky Olomouc Czech Repub 150(2): 279-283.

21. Waterstone M, Bewley S, Wolfe C (2001) Incidence and predictors of severe obstetric morbidity: case-control study. BMJ 322(7294): 10891093.

22. Moodley J, Pattinson R (2001) Saving mothers. Second report on confidential enquiries into maternal deaths in South Africa, 1999-2001. 